\section{Estimation of barium sulphate in faeces by emission flame photometry}

\author{
MATTHEW DICK From the Metabolic Unit, \\ University College Hospital, London
}

The estimation of barium sulphate (Dick, 1967) as a continuous marker in faeces is based upon a gravimetric method which is rather time consuming. The present paper describes a flame photometric modification which greatly simplifies the analysis.

\section{REAGENTS AND APPARATUS}

AMMONIUM SULPHATE A $5 \%$ solution in $1 \mathrm{~N} \mathrm{HCl}$.

TETRAMETHYLAMMONIUM HYDROXIDE A $25 \%$ aqueous solution (TMAH).

ETHYLENEDIAMINETETRA-ACETIC ACID DIAMMONIUM SALT $5 \%$ in water (ammonium EDTA).

STOCK BARIUM STANDARD (EQUIVALENT TO $400 \mathrm{mg} \%$ $\mathrm{BaSO}_{4}$ ) Dissolve $2.0935 \mathrm{~g}$ of $\mathrm{BaCl}_{2} \cdot 2 \mathrm{H}_{2} \mathrm{O}$ in $500 \mathrm{ml}$ water.

WORKING STANDARD (EQUIVALENT TO $40 \mathrm{mg} . \% \mathrm{BaSO}_{4}$ ) Take $10 \mathrm{ml}$ stock standard, $20 \mathrm{ml}$ ammonium EDTA, and $6 \mathrm{ml}$ TMAH and make up to $100 \mathrm{ml}$.

BLANK Ammonium EDTA, $20 \mathrm{ml}$, and $6 \mathrm{ml}$ TMAH in $100 \mathrm{ml}$.

An Eppendorf flame photometer burning an acetyleneair mixture was used. The wavelength was $510 \mathrm{~m} \mu$, using a multilayer interference filter.

\section{METHODS}

The barium sulphate was sieved through an 85 mesh sieve and administered with meals as $1 \mathrm{~g}$ per day packed in three gelatin capsules. Stools were analysed in four-day pools, the weight of the homogenate being adjusted to contain approximately $1 \mathrm{mg} \mathrm{BaSO}$ per $\mathrm{g}$ of homogenate, and samples for analysis in the region of $20 \mathrm{~g}$ were taken in silica beakers. These samples were dried at $95^{\circ} \mathrm{C}$ and

Received for publication 12 July 1968. ashed in a muffle furnace at $600^{\circ} \mathrm{C}$ for at least three hours.

Of the acid ammonium sulphate, $10 \mathrm{ml}$, and $30 \mathrm{ml}$ of water are added to the ashed sample, and after warming to dissolve soluble material the contents are decanted with washing into a $50 \mathrm{ml}$ centrifuge tube, the $\mathrm{BaSO}_{4}$ being washed into the tube as far as possible. The tube is centrifuged for $5 \mathrm{~min}$, the supernatant decanted off and the tube allowed to drain. If necessary the supernatant (plus washings) may be used for the analysis of soluble minerals such as calcium. Meanwhile $10 \mathrm{ml}$ of ammonium EDTA and $3 \mathrm{ml}$ TMAH are added to the silica beaker which is then warmed on a steam bath for $10 \mathrm{~min}$ to dissolve any remaining $\mathrm{BaSO}_{4}$. The contents of the beaker are transferred to the tube with washing, and the tube placed in a boiling water bath for about 10 min with occasional stirring. The solution is cooled, made up to $50 \mathrm{ml}$, and filtered (if necessary) before flame photometry which is carried out in the usual manner.

\section{RESULTS}

In six experiments in which $\mathrm{BaSO}_{4}$ was added to stools already in the homogeniser the recoveries were : (1) $98.2 \%$; (2) $100.1 \%$; (3) $99.6 \%$; (4) $101.7 \%$; (5) $99.8 \%$; (6) $99.1 \%$, the mean being $99.7 \%$.

COMMENT

The estimation of barium by emission flame photometry suffers from the disadvantage of poor sensitivity, and hence to interference from other elements, especially sodium. This has been overcome, first by an acid extraction which removes soluble elements, and secondly by chelating the barium with an ammonium salt of EDTA and a strong organic base. Thus barium solutions of sufficient concentration to give good sensitivity may be employed in the presence of a very low 'blank' value.

The time involved in analysis by this method is considerably reduced compared to that of Dick (1967), and is comparable to those methods employing chromium oxide. The latter methods have the disadvantage of a perchloric acid oxidation from which a number of explosions have occurred.

Professor C. E. Dent supervised this work. Thanks are also due to Dr Lyal Watson and to the nursing and dietetic staff of the Metabolic Unit.

REFERENCE

Dick, M. (1967). J. clin. Path., 20, 216. 